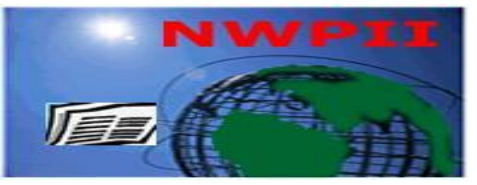

American Journal of Biomedical Sciences

ISSN: 1937-9080

nwpii.com/ajbms

\title{
Upregulation of TNF-alpha and Receptors Contribute to Endothelial Dysfunction in Zucker Diabetic Rats
}

\author{
Xue Gao, Andrea Picchi, and Cuihua Zhang*
}

Departments of Internal Medicine, Medical Pharmacology \& Physiology and Nutritional Sciences, Dalton

Cardiovascular Research Center, University of Missouri-Columbia, Columbia, MO 65211

*Corresponding author

Cuihua Zhang, MD, PhD

Departments of Internal Medicine, Medical

Pharmacology \& Physiology and Nutritional Sciences

Dalton Cardiovascular Research Center

University of Missouri

Columbia, MO 65211

Phone: 573-882-2427 (O); 573-884-6208 (Lab)

Fax: 573-884-4232

E-mail address: ZhangCu@missouri.edu

Received: 28 February 2009; $\mid$ Revised: 30 June 2009; $\mid$ Accepted: 22 July 2009

\begin{abstract}
Diabetes mellitus is a major risk factor to impair endothelial function and induce cardiovascular diseases. TNF-alpha (TNF) is expressed during a variety of inflammatory conditions. We hypothesized that impairment in coronary endothelial function in type 2 diabetes is due to the overexpression of TNF and TNF receptors (TNFRs). Endothelium-dependent (acetylcholine, $\mathrm{ACh}$ ) and -independent vasodilation (sodium nitroprusside, SNP) of isolated, pressurized $\left(60 \mathrm{cmH}_{2} \mathrm{O}\right)$ coronary arteries $(50-100 \mu \mathrm{m})$ from lean control and Zucker diabetic fatty (ZDF, the model of type 2 diabetes) rats were determined. In lean rats, SNP and ACh induced dose-dependent vasodilation, but dilation to only ACh was blocked by the NOS inhibitor $\mathrm{N}^{\mathrm{G}}$-monomethyl-L-arginine (L-NMMA, $10 \mu \mathrm{M})$. In $\mathrm{ZDF}$ rats, dilation to $\mathrm{ACh}$ was blunted compared to lean rats, but SNP-induced dilation was comparable. Neutralizing antibodies to $\mathrm{TNF}$, or blockade of $\mathrm{NAD}(\mathrm{P}) \mathrm{H}$ and xanthine oxidase, partially restored endothelium-dependent, NO-mediated vasodilation in isolated coronary arteries in ZDF rats, but anti-TNF did not alter endothelium-dependent vasodilation in lean rats. The mRNA expression of TNF receptor 1 (TNFR1, but not TNFR2) significantly increased in coronary arteries in ZDF rats. Protein expression of TNF and N-Tyr $\left(\mathrm{ONOO}^{-}\right)$ were higher in coronary arteries in ZDF than those in lean rats. Production of $\mathrm{H}_{2} \mathrm{O}_{2}, \mathrm{NAD}(\mathrm{P}) \mathrm{H}$ oxidase and xanthine oxidase activity were all higher in ZDF rats than those in lean controls; anti-TNF reduces the production of $\mathrm{H}_{2} \mathrm{O}_{2}$, N-Tyr expression, $\mathrm{NAD}(\mathrm{P}) \mathrm{H}$ oxidase and xanthine oxidase activity in ZDF rats. These results demonstrate the endothelial dysfunction occurring in type 2 diabetes is the result of effects of the inflammatory cytokine TNF that activates $\mathrm{NAD}(\mathrm{P}) \mathrm{H}$ oxidase and xanthine oxidase; and perhaps acts mainly through the overexpression of TNFR1.
\end{abstract}

Keywords: Microcirculation, coronary artery disease, nitric oxide. 


\section{INTRODUCTION}

Diabetes mellitus is associated with a significant increase incidence in the development of cardiovascular diseases. Vascular disease, particularly of the coronary arteries, is the major cause of morbidity and mortality in type 2 diabetic subjects (4). Diabetes impaired endotheliumdependent relaxation in rabbit aorta in vitro (21, $22)$, and the cerebral circulation in vivo $(10,11)$. Function of vasodilation in intestinal and skeletal muscle vessels were decreased in type 2 diabetes $(8,13)$. However, few investigations into the dysfunction of heart coronary arteries have been conducted in diabetes. TNF is one of the key inflammatory mediators expressed during a variety of inflammatory conditions, and takes part in a variety of physiological and pathological phenomena. For example, TNF expression was increased in coronary arteries in hyperhomocysteinemia, an independent risk factor for coronary artery disease $(15,19)$. The titer of TNF in circulation increased in weight-gaining rats, but decreased in weight-losing rats (6).

TNF initiates inflammatory responses by binding to two distinct cell surface receptors of 55 $\mathrm{kDa}$ (TNFR1) and $75 \mathrm{kDa}$ (TNFR2) (20). The increase in membrane and soluble receptors together with an increase in the presence TNF could increase signaling activity into cells. However, little information is available regarding the role of TNF in endothelial dysfunction of coronary arteries in advanced type 2 diabetes. Accordingly, we are initiating exploration of whether type 2 diabetes-induced coronary endothelial dysfunction is mediated by TNF and/or TNFRs, the elucidation of the mechanisms involved in this abnormality, and further deciphering the expression and cellular sources for TNF in Zucker diabetic fatty (ZDF, the model of type 2 diabetes) rats. The basal superoxide $\left(\mathrm{O}_{2}{ }^{\cdot-}\right)$ release was significantly elevated in vessels from patients with diabetes (5). $\mathrm{O}_{2}{ }^{-}$can lead to formation of other reactive oxidative species (ROS) such as hydrogen peroxide $\left(\mathrm{H}_{2} \mathrm{O}_{2}\right)$ and peroxynitrite $\left(\mathrm{ONOO}^{-}\right)$. We also tested the mechanisms by which TNF/TNFR -induces endothelial dysfunction, and the role of ROS
$\left(\mathrm{O}_{2}{ }^{-}, \mathrm{H}_{2} \mathrm{O}_{2}, \mathrm{ONOO}^{-}\right)$in coronary arteries in advanced type 2 diabetes

\section{MATERIALS AND METHODS}

Animal models of type 2 diabetes. Twenty six to thirty two weeks old, $400 \pm 50 \mathrm{~g}$ lean and $900 \pm 100$ g ZDF (Charles Rivers) male rats were used. The ZDF rat was an inbred rat model that through genetic mutation and a managed diet of Purina 5008 will closely mimic human adult onset diabetes (type 2) and related complications. Additionally, nature and fat content of Purina 5008 diet. When fed a diet of Purina 5008, homozygous recessive males (fa/fa) developed obesity, hyperlipidemia, fasting hyperglycemia and type 2 diabetes. Homozygous dominant $(+/+)$ and heterozygous $(\mathrm{fa} /+)$ lean genotypes remained normoglycemic. The ZDF rat was an accurate model for type 2 diabetes based on impaired glucose tolerance caused by the inherited obesity gene mutation, which leads to insulin resistance. Neutralizing antibody experiments were conducted on both lean Zucker (the control rat is from the same genetic background as the ZDF) and ZDF rats. We defined 26 to 32 weeks old ZDF rats as advanced type 2 diabetic rats in this study.

Treatment with TNF neutralization. The neutralizing antibody to TNF (anti-TNF) (9) used in these studies is 2E2 monoclonal antibody (2E2 MAb. 94021402, NCI Biological Resources Branch). At 26-32 weeks of age, all rats received the neutralizing anti-TNF (2E2 MAb. 0.625 $\mathrm{mg} / \mathrm{ml} / \mathrm{kg} /$ day, 3 days, i.p.) (16). The rationale for this dose of antibody was based on our estimates of TNF expression (in the low ng or pg range) and this dose is able to neutralize $10-100$ fold this amount of TNF.

Functional assessment of isolated small coronary arteries. A branch of the septal coronary artery $(40-100 \mu \mathrm{m}$ in diameter; $\sim 0.5 \mathrm{~mm}$ in length) was carefully dissected for in vitro study as described previously (16). Vessels were then cannulated with glass micropipettes, pressurized to $60 \mathrm{~cm} \mathrm{H}_{2} \mathrm{O}$ intraluminal pressure, and bathed in physiological salt solution (PSS). The inner diameters of coronary artery were measured using video microscopic techniques. After developing a 
stable basal tone (i.e., spontaneous constriction to $60-70 \%$ of maximal diameter), the experimental interventions were performed. The concentrationdiameter relationships for $\mathrm{ACh}(0.1 \mathrm{nmol} / \mathrm{L}$ to 10 $\mu \mathrm{mol} / \mathrm{L})$ and SNP $(1 \mathrm{nmol} / \mathrm{L}$ to $1 \mu \mathrm{mol} / \mathrm{L})$ were then established. The contributions of the NO pathway in these vasodilations were examined by treating the vessels with the NOS inhibitor $\mathrm{N}^{\mathrm{G}}$ monomethyl-L-arginine (L-NMMA, $10 \mu \mathrm{mol} / \mathrm{L}$, 30-minute incubation). We tested the doseresponse curve to flow-induced dilation (FID, range of $\Delta \mathrm{P}$ [that is linearly related to flow] from 4 to $60 \mathrm{~cm} \mathrm{H} \mathrm{H}_{2} \mathrm{O}$ ), a response that is endothelial dependent, but agonist independent.

To determine whether TNF was playing a role in endothelial injury in the type 2 diabetes, endothelial dependent and independent dilation was assessed in coronary arteries from anti-TNF treated rats. To determine the role of TNF and $\mathrm{O}_{2}{ }^{-}$anion in type 2 diabetes, the above vasodilatory functions were examined in the presence of inhibitors of ROS. The contribution of $\mathrm{NAD}(\mathrm{P}) \mathrm{H}$ oxidase, xanthine oxidase and mitochondrial respiratory chain in generating $\mathrm{O}_{2}{ }^{.-}$ in type 2 diabetes were assessed by treating the vessels with an $\mathrm{NAD}(\mathrm{P}) \mathrm{H}$ oxidase inhibitor apocynin $(10 \mu \mathrm{mol} / \mathrm{L})$, a xanthine oxidase inhibitor oxypurinol $(100 \mu \mathrm{mol} / \mathrm{L})$ or the mitochondrial respiratory chain inhibitor rotenone (1 $\mu \mathrm{mol} / \mathrm{L})$ for 60 -minute incubation, separately (25). All drugs were administered extraluminally in these functional studies.

$R N A$ extraction and reverse transcription polymerse chain reaction (RT-PCR) analysis. The mRNA expression of TNFR1 and TNFR2 were estimated by a semiquantitative RT-PCR assay. Total RNA was extracted from isolated coronary arteries in ZDF and lean rats (4-6 vessels) using Trizol reagent (Life Technologies Inc), and was processed directly to cDNA synthesis using the SuperScript $^{\mathrm{TM}}$ III Reverse Transcriptase (Life Technologies Inc). The single-strand cDNA was amplified by PCR with Taq DNA polymerase. The sequences of sense and antisense primers, respective PCR conditions, and cycle counts were as follows: TNFR1, sense: accaagtgccacaaaggaac, antisense: ctggaaatgcgtctcactca, $1 \mathrm{~min}$ at $94^{\circ} \mathrm{C}$, $1 \mathrm{~min}$ at $55^{\circ} \mathrm{C}$, and $1 \mathrm{~min}$ at $72^{\circ} \mathrm{C}, 35$ cycles; TNFR2, sense: aaatgcaagcacagatgcag, antisense: cagcagacccagagttgtca, $1 \mathrm{~min}$ at $94^{\circ} \mathrm{C}, 1 \mathrm{~min}$ at $55^{\circ} \mathrm{C}$, and $1 \mathrm{~min}$ at $72^{\circ} \mathrm{C}, 35$ cycles. GAPDH cDNA was amplified as a control.

Protein expression of TNF and nitrotyrosine $(N-T y r)$ by western blot analyses. For western blot analysis, isolated coronary arteries (4-6 vessels) were separately homogenized and sonicated in lysis buffer (Cellytic ${ }^{\mathrm{TM}}$ MT Mammalian Tissue Lysis/Extraction Reagent, Sigma). Protein concentrations were assessed with use of $\mathrm{BCA}^{\mathrm{TM}}$ Protein Assay Kit (Pierce), and equal amounts of protein $(40 \mu \mathrm{g})$ were separated by SDS-PAGE and transferred to nitrocellulose membranes (Hybond, Amersham). TNF and N-Tyr (an indicator for peroxynitrite-mediated tissue injury) protein expression were detected by western blot analysis with use of TNF primary antibodies (Santa Cruz) and N-Tyr primary antibodies (Abcam) in lean, ZDF rats, ZDF rats treated with anti-TNF $(0.625$ $\mathrm{mg} / \mathrm{ml} / \mathrm{kg}$ /day, 3 days, i.p.), or ZDF rats treated with TEMPOL (100 mg/kg/day, 7 days, i.p.). Horseradish peroxidase-conjugated antibodies (Abcam) were used as secondary antibodies. Signals were visualized by enhanced chemiluminescence (ECL, Amersham), and quantified by Quantity One (BioRad Versadoc imaging system).

Electron paramagnetic resonance (EPR) spectroscopy. Superoxide quantitation from the EPR spectra was determined in the homogenate (4-6 isolated coronary arteries each group) as described previously (16) in lean, ZDF rats, ZDF rats treated with anti-TNF $(0.625 \mathrm{mg} / \mathrm{ml} / \mathrm{kg} /$ day, 3 days, i.p.), or ZDF rats treated with TEMPOL (100 mg/kg/day, 7 days, i.p.).

$N A D(P) H \quad$ oxidase activity. $\quad \mathrm{NAD}(\mathrm{P}) \mathrm{H}$ oxidase activity was assayed in protein isolated from coronary arteries extracts as initiated by the addition of $50 \mu \mathrm{mol} / \mathrm{L} \quad \mathrm{N}, \quad \mathrm{N}$-dimethyl-9, 9biacridinium dinitrate (Lucigenin) (Sigma, St. Louis, MO, USA) to the incubation mixture. Samples were counted immediately using a table top luminometer and fluorescence values were averaged from 2 minutes of stable readings for that sample. Samples from lean, ZDF rats, ZDF rats treated with anti-TNF $(0.625 \mathrm{mg} / \mathrm{ml} / \mathrm{kg} /$ day, 3 days, i.p.), or ZDF rats treated with apocynin (100 $\mathrm{mg} / \mathrm{kg} /$ day, 3 days, i.p.) were run in duplicate and 
the NAD $(\mathrm{P}) \mathrm{H}$ oxidase activity was normalized to the lean control rats.

Xanthine oxidase activity. Xanthine oxidase activity was measured by Amplex red xanthine /xanthine oxidase assay kit (A22182) from Invitrogen according to the kit protocol. Protein isolated from coronary arteries was used as the sample. Absorbance was read at $560 \mathrm{~nm}$ using spectrophotometer. Xanthine oxidase activity was normalized to the lean control rats.

Measurement of $\mathrm{H}_{2} \mathrm{O}_{2}$. Production of $\mathrm{H}_{2} \mathrm{O}_{2}$ was determined by using the Assay Kit (R \& D Systems). Serum was obtained from lean, ZDF, ZDF rats treated with $\mathrm{H}_{2} \mathrm{O}_{2}$ inhibitor catalase (10,000 U/day, 3 days, i.p.) and ZDF rats treated with anti-TNF $(0.625 \mathrm{mg} / \mathrm{ml} / \mathrm{kg} /$ day, 3 days, i.p. $)$. The $\mathrm{H}_{2} \mathrm{O}_{2}$ concentration was then determined by measuring the optical density of the solution in each well (microplate reader set to $550 \mathrm{~nm}$ ).

Statistical analysis. At the end of each experiment, the vessel was relaxed with 100$\mu \mathrm{mol} / \mathrm{L}$ SNP to obtain its maximal diameter at 60 $\mathrm{cm} \mathrm{H}_{2} \mathrm{O}$ intraluminal pressure. All diameter changes in response to agonists were normalized to the vasodilation in response to $100 \mu \mathrm{mol} / \mathrm{L} \mathrm{SNP}$ and expressed as a percentage of maximal dilation. All data are presented as mean \pm SEM, except as specifically stated (e.g. as mean \pm SD for molecular study). Statistical comparisons of vasomotor responses under various treatments were performed with one-way or two-way ANOVA and intergroup differences were tested with Bonferonni Inequality. Significance was accepted at $\mathrm{P}<0.05$.

\section{RESULTS}

Plasma concentrations of glucose, blood pressure, body weights, abdominal girth, lipid level and insulin resistance. Plasma parameters (Table 1) were measured at 26-32 weeks in different strains of the rats. Body weight, abdominal girth, glucose concentration and cholesterol were higher in ZDF compared with lean rats. In anti-TNF treated ZDF rats, no differences were observed in body weight, abdominal girth, blood glucose or lipid level compared with lean rats. Insulin level and blood pressure did not differ among the animals on the day of surgery.

Table 1. The Parameters in the Different Strains of Rats:

\begin{tabular}{llll}
\hline Groups & \multicolumn{1}{c}{ lean } & ZDF & ZDF+anti-TNF \\
\hline Body Weight, g & $400 \pm 50$ & $900 \pm 100^{*}$ & $900 \pm 60^{*}$ \\
Abdominal Girth, cm & $16 \pm 0.8$ & $22 \pm 0.6^{*}$ & $23 \pm 0.6^{*}$ \\
Lipid Level, (normalize unit) & 1 & $4 \pm 0.5^{*}$ & $3 \pm 0.21^{*}$ \\
Blood Glucose, $\mu \mathrm{g} / \mathrm{mL}$ & $140 \pm 20$ & $530 \pm 50^{*}$ & $526 \pm 42^{*}$ \\
Plasma Insulin, $\mathrm{ng} / \mathrm{ml}$ & $0.2 \pm 0.01$ & $0.12 \pm 0.02$ & $0.12 \pm 0.02$ \\
Blood Pressure, mm Hg & $120 \pm 4$ & $129 \pm 6$ & $126 \pm 3$ \\
& & & \\
\hline
\end{tabular}

Metabolic values from lean, ZDF, and ZDF rats treated with anti-TNF than those in lean rats. Data are represented as means $\pm \mathrm{SD}$. $* \mathrm{P}<0.05$ vs lean rats; $\mathrm{n}=10$

Effects of type 2 diabetes on NO-mediated vasodilation to $A C h$. Isolated rat coronary arteries from lean control rats dilated in a concentrationdependent manner to ACh. The NOS inhibitor, LNMMA $\quad(10 \mu \mathrm{mol} / \mathrm{L}, \quad 30 \mu \mathrm{min})$ inhibited vasodilation to $\mathrm{ACh}$ vs control (Figure 1A). However, ACh-induced vasodilation was blunted in arteries from ZDF rats, and L-NMMA did not further affect this response (data not shown), suggesting that NO production or bioavailabilty is impaired in type 2 diabetes. Figure 1B shows abrogated FID (flow-induced dilation) in ZDF rats compared to leans. We also studied the role of TNF in the type 2 diabetes-induced vascular dysfunction. Figure 1 shows that neutralizing antibodies to TNF restored NO-mediated 
vasodilation (ACh-induced and flow-induced) in ZDF rats; vasodilation in lean rats remained normal (Figure 1A \& 1B). This observation is the cornerstone of our hypothesis that overexpression of this inflammatory cytokine produces endothelial dysfunction in type 2 diabetes. In contrast, SNP-induced vasodilation was normal in both lean and ZDF rats (data not shown). These data indicate the vasodilation to $\mathrm{ACh}$ is endothelium-dependent, and NO-mediated in rat coronary arteries.
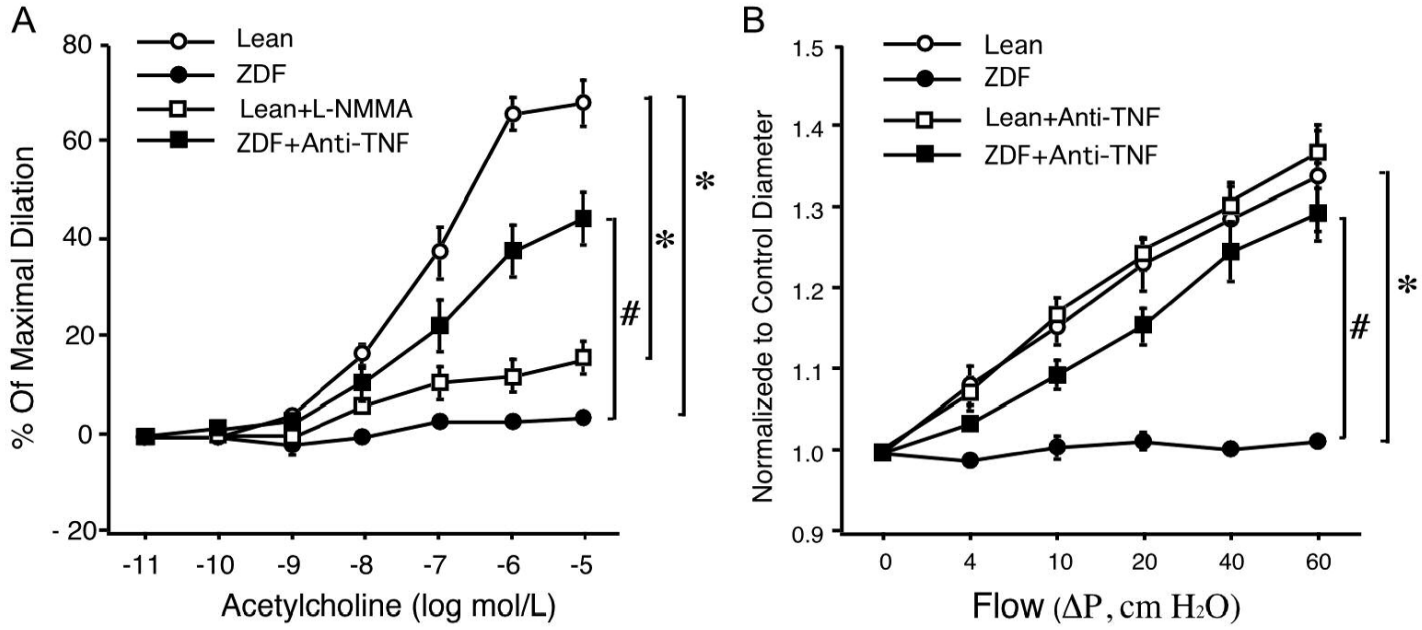

Figure 1. Isolated coronary arteries from lean rats dilated in a concentration-dependent manner to ACh. The NOS inhibitor, L-NMMA (30 min, $\mathrm{n}=8$ ) inhibited vasodilation to ACh vs control (Figure 1A). In a similar manner with LNMMA, ACh-induced vasodilation was blunted in coronary arteries from ZDF vs lean contrls ( $\mathrm{n}=8$, Figure 1A). AntiTNF restored NO-mediated coronary arteriolar dilation in ZDF rats $(n=6)$, but did not affect the vasodilation to ACh in lean rats (data not shown, $n=6$ ). Figure 1B shows that FID was abrogated in ZDF rats $(n=5)$, but similar to the response for ACh, anti-TNF restored FID to near control levels $(n=5)$. Anti-TNF did not affect the vasodilation of control vessels. $* \mathrm{P}<0.05$ vs lean rats and $\# \mathrm{P}<0.05$ vs $\mathrm{ZDF}$ rats.

Protein and mRNA expression of TNF and TNFRs. Western blot results show the protein expression of TNF was increased in isolated small coronary arteries in ZDF rat compared to lean control (Figure 2A). RT-PCR analysis showed that the mRNA expression of TNFR1 was increased significantly in ZDF rat coronary arteries (Figure 2B), but the mRNA expression of TNFR2 was not different in coronary arteries isolated from $\mathrm{ZDF}$ and lean rats as shown in Figure 2C. The levels of mRNA encoding for GAPDH were not found to be significantly different between groups. These results corroborate the functional results shown in Figure 1.

Roles of ROS in type 2 diabetes-induced vascular dysfunction. To establish the pathway for $\mathrm{O}_{2}{ }^{--}$production, we administered $\mathrm{O}_{2}{ }^{\cdot-}$ scavenger with $\mathrm{NAD}(\mathrm{P}) \mathrm{H}$ oxidase inhibitor apocynin (10 $\mu \mathrm{mol} / \mathrm{L})$, xanthine oxidase inhibitor oxypurinol $(100 \mu \mathrm{mol} / \mathrm{L})$ or the mitochondrial respiratory chain inhibitor rotenone (1 $\mu \mathrm{mol} / \mathrm{L}$, data not shown), to determine if vasodilation to ACh would be restored by inhibiting of ROS in ZDF rats (Figure 3A). Administration of apocynin restored impaired vasodilation to $\mathrm{ACh}$ in $\mathrm{ZDF}$ rats; administration of apocynin+oxypurinol further restored impaired vasodilation to $\mathrm{ACh}$ to the lean control level in ZDF rats, but rotenone did not affect the impaired vasodilation (data not shown).

We also examined the roles of $\mathrm{H}_{2} \mathrm{O}_{2}$ in the presence of $\mathrm{H}_{2} \mathrm{O}_{2}$ inhibitor catalase $(10,000 \mathrm{U} / \mathrm{ml})$ or $\mathrm{ONOO}^{-}$with $\mathrm{ONOO}^{-}$scavenger ebselen (10 $\mu \mathrm{mol} / \mathrm{L}$, glutathione peroxidase mimetic) in ZDF rats (Figure 3B). Ebselen or catalase also restored impaired vasodilation to $\mathrm{ACh}$ in $\mathrm{ZDF}$ rats, but did not affect the vasodilation in lean rats (data not shown).

Type 2 diabetes-induced production of superoxide and $\mathrm{H}_{2} \mathrm{O}_{2}$ in coronary arteries in type 2 diabetes. Figure 4A showed the results from 
EPR spectroscopy quantifying the production of $\mathrm{O}_{2} \cdot{ }^{-}$was increased in ZDF rat compared to lean and reflect agreement with those obtained by the functional data discussed above. Figure 4B showed elevation in $\mathrm{H}_{2} \mathrm{O}_{2}$ production in $\mathrm{ZDF}$ rats compared to the lean control rats. Treatment with anti-TNF or catalase reduced $\mathrm{H}_{2} \mathrm{O}_{2}$ production in the ZDF rats.
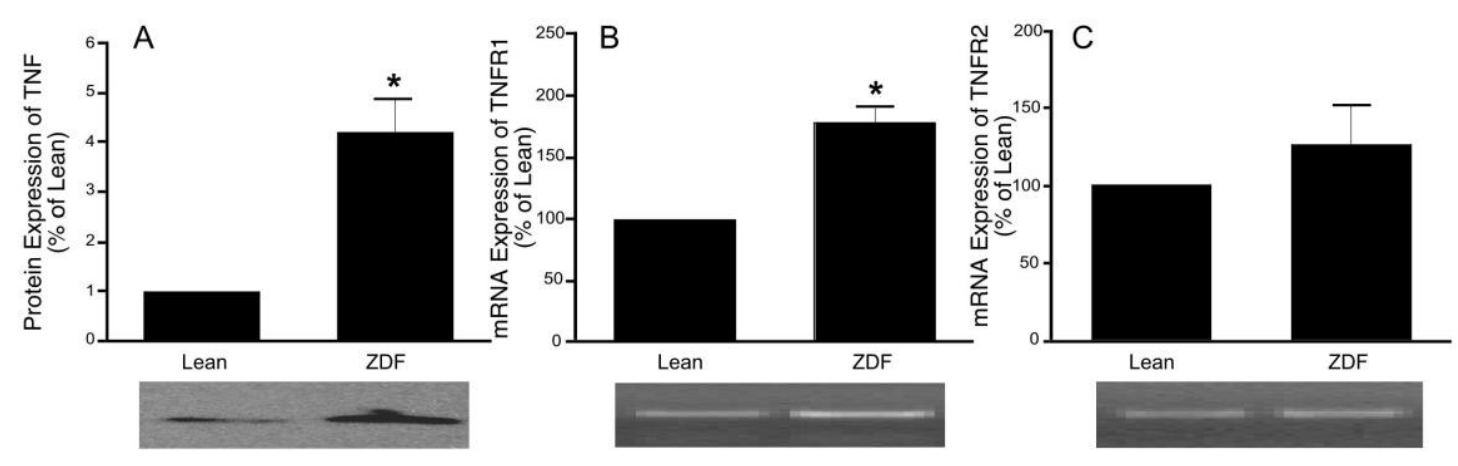

Figure 2. Western blot analysis of TNF protein level in isolated coronary arteries from lean and ZDF rats. As shown in Figure $2 \mathrm{~A}$, we found that protein expression of TNF $(17 \mathrm{kD})$ was significantly increased in isolated coronary arteries in ZDF rats compared to lean rats. Data represent means \pm SD from 3 different experiments. $* \mathrm{P}<0.05$ vs. lean rats. As shown from Figure 2B and 2C, mRNA expression of TNFR1 (Figure 2B) was significantly increased in coronary arteries from ZDF rat, but the mRNA expression of TNFR2 (Figure 2C) has no differences between ZDF and lean rats. The levels of mRNA encoding for GAPDH were not found to be significantly different between the groups. Data represent means $\pm \mathrm{SD}$ from 3 different experiments. $* \mathrm{P}<0.05$ vs. lean rats.
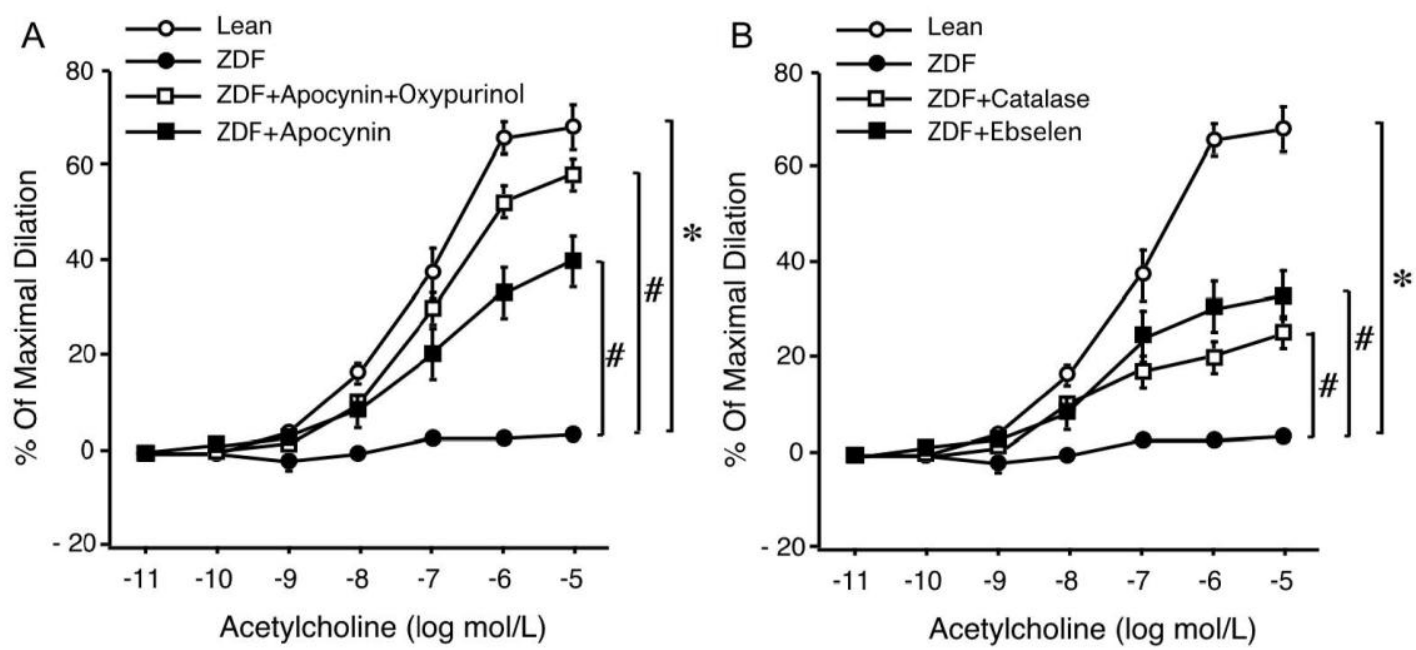

Figure 3. Apocynin (Figure 3A) partially restored vasodilation in ZDF rats, but administration of apocynin and oxypurinol (xanthine oxidase inhibitor) improved vasodilation to the control level in ZDF rats. Administration of ebselen (Figure 3B) or catalase (Figure 3B) also restored impaired vasodilation to ACh in ZDF rats, but did not affect the vasodilation in lean rats (data not shown). ${ }^{*} \mathrm{P}<0.05$ vs lean rats and $\# \mathrm{P}<0.05$ vs $\mathrm{ZDF}$ rats. 

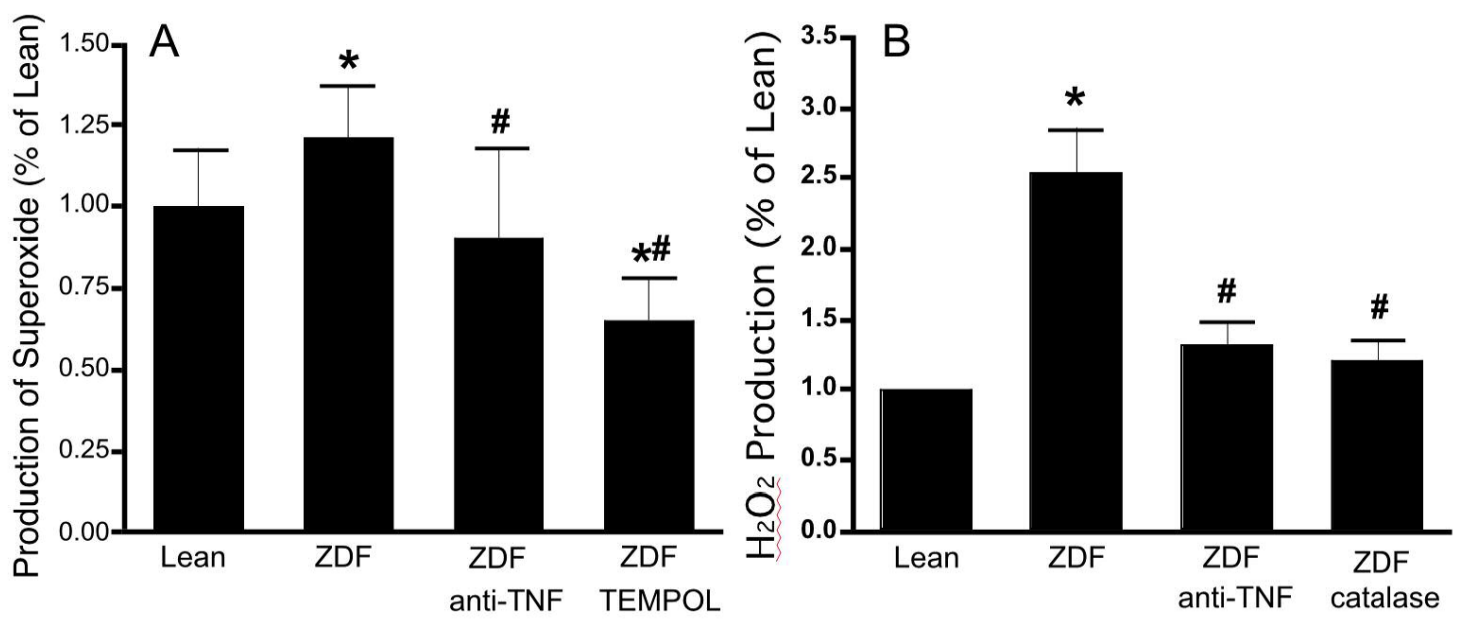

Figure 4. Figure 4A shows the results from EPR spectroscopy to quantify the production of $\mathrm{O}_{2}{ }^{-}$. The production of $\mathrm{O}_{2}{ }^{-}$was higher in isolated coronary arteries from ZDF vs lean rats $(\mathrm{n}=9)$. Administration of anti-TNF reduced the production of $\mathrm{O}_{2}{ }^{\cdot-}$ to the level observed in the lean rats. Figure 4B shows that $\mathrm{H}_{2} \mathrm{O}_{2}$ production $(\mathrm{n}=7)$ is higher in $\mathrm{ZDF}$ than that in lean rats. Anti-TNF reduced the production of $\mathrm{H}_{2} \mathrm{O}_{2}$ in ZDF rats. Catalase greatly attenuated $\mathrm{H}_{2} \mathrm{O}_{2}$ production in ZDF rats without affecting of $\mathrm{H}_{2} \mathrm{O}_{2}$ production in lean rats, and thus showing specificity of the measurement for the particular $\mathrm{H}_{2} \mathrm{O}_{2}$ production. ${ }^{*} \mathrm{p}<0.05$ vs lean rats and $\# \mathrm{p}<0.05$ vs $\mathrm{ZDF}$ rats.
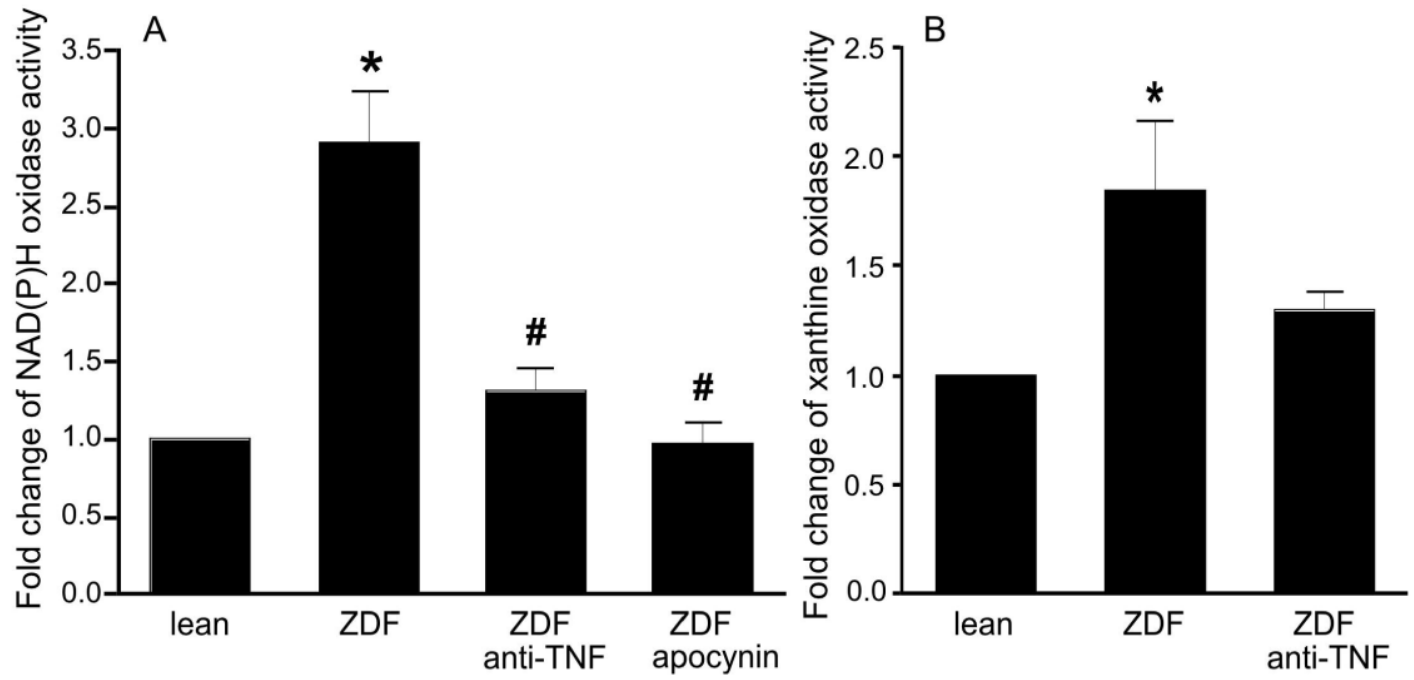

Figure 5. $\mathrm{NAD}(\mathrm{P}) \mathrm{H}$ oxidase activity was higher in $\mathrm{ZDF}$ than that in lean control rats. Treatment by apocynin or by anti-TNF significantly decreased NAD $(\mathrm{P}) \mathrm{H}$ oxidase activity in ZDF rats (Figure 5A, n=8), separately. Bars represent the increased $\mathrm{NAD}(\mathrm{P}) \mathrm{H}$ oxidase activity in $\mathrm{ZDF}$ rats as a fold change of lean control. Figure $5 \mathrm{~B}$ shows us xanthine oxidase activity was also higher in ZDF rats than that in lean rat and anti-TNF treatment could attenuate the increased activity in ZDF rats ( $\mathrm{n}=8)$.

Type 2 diabetes increased $N A D(P) H$ oxidase and xanthine oxidase activity. $\mathrm{NAD}(\mathrm{P}) \mathrm{H}$ oxidase activity from isolated coronary arteries is normal in lean and elevated in ZDF rats (Figure 5A). The treatment of anti-TNF $(0.625 \mathrm{mg} / \mathrm{ml} / \mathrm{kg} /$ day, 3 days, i.p.) or apocynin $(100 \mathrm{mg} / \mathrm{kg} / \mathrm{day}, 3$ days, 
i.p.) significantly reduced $\mathrm{NAD}(\mathrm{P}) \mathrm{H}$ oxidase activity in ZDF rats, but did not affect NAD $(\mathrm{P}) \mathrm{H}$ oxidase activity in lean rats (data not shown). Figure 5B shows that xanthine oxidase activity was increased in ZDF rats, and anti-TNF attenuated xanthine oxidase activity in ZDF rats without affecting xanthine oxidase activity in lean rats (data not shown).

Type 2 diabetes-induced $\mathrm{ONOO}^{-}$in coronary arteries isolated from $Z D F$ rats. The short half-life of $\mathrm{ONOO}^{-}$precludes direct measurement, thus an index of its formation was obtained by western blotting for N-Tyr. Western blot analysis (Figure 6) for N-Tyr in homogenates from lean, ZDF, antiTNF treated ZDF, and TEMPOL treated ZDF rats, revealed significantly higher levels of N-Tyr in ZDF rats, which was reduced to lean control levels by anti-TNF or TEMPOL.
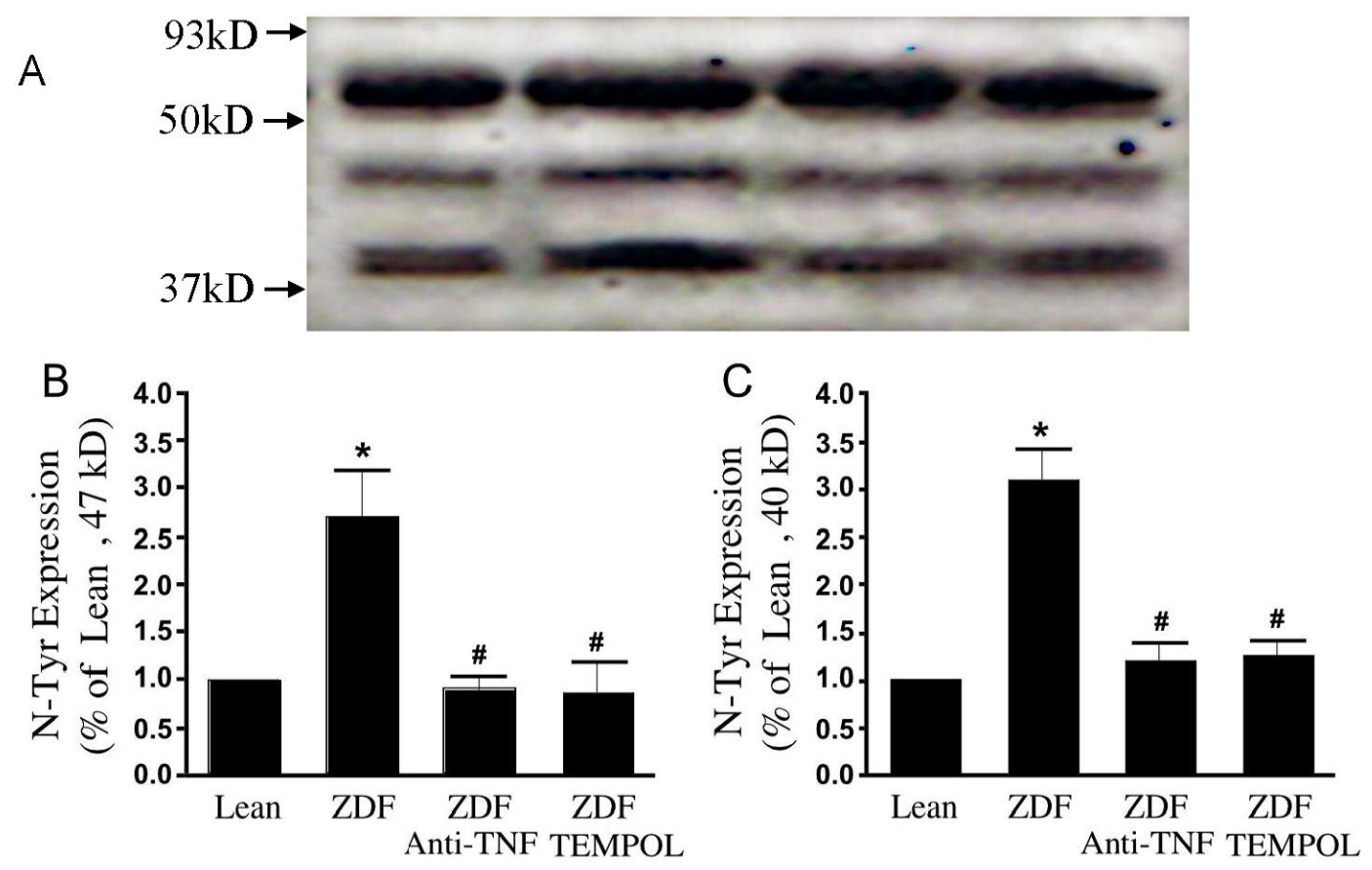

Figure 6. Figure 6A shows a typical N-Tyr blot; the arrows point to the analyzed bands. We analyzed bands of N-Tyr migrating at 47 and $40 \mathrm{kD}(\mathrm{n}=4)$. In graphs $\mathrm{B}$ and $\mathrm{C}$, the results are shown for $\mathrm{N}-\mathrm{Tyr}$ bands migrating at 47 and $40 \mathrm{kD}$ respectively. Figures $6 \mathrm{~B}$ and $6 \mathrm{C}$ show that both 47 and $40 \mathrm{kD}$ of N-Tyr are higher in ZDF than those in lean rats, after administration of anti-TNF or TEMPOL, both bands of N-Tyr are decreased in ZDF rats. *p $<0.05$ vs lean rats, $\# \mathrm{p}<0.05$ vs ZDF rats.

\section{DISCUSSION}

Our results suggest that the over-expression of inflammatory cytokine, TNF and TNFR1 leads to oxidative stress via $\mathrm{NAD}(\mathrm{P}) \mathrm{H}$ and xanthine oxidase activation, and perhaps by activating $\mathrm{ONOO}^{-}$and $\mathrm{H}_{2} \mathrm{O}_{2}$, which in turn may lead to TNF expression inducing endothelial dysfunction in ZDF rats (a model for obesity and type 2 diabetes). Importantly, our findings support the concept that TNF plays a pivotal role in endothelial dysfunction in advanced type 2 diabetes based on the following observations: antibody neutralization of TNF prevented coronary endothelial dysfunction, and reduced $\operatorname{ROS}\left(\mathrm{O}_{2}{ }^{-}\right.$, $\mathrm{ONOO}^{-}$and $\left.\mathrm{H}_{2} \mathrm{O}_{2}\right)$ production in $\mathrm{ZDF}$ rats. Blockade of $\mathrm{NAD}(\mathrm{P}) \mathrm{H}$ oxidase and xanthine oxidase mimicked the actions of antiTNF on endothelial function in ZDF rats. Molecular evidence indicated that the expression of TNF and TNFR1, production of $\operatorname{ROS}\left(\mathrm{O}_{2}{ }^{-}\right.$, $\mathrm{H}_{2} \mathrm{O}_{2}$, and $\mathrm{ONOO}^{-}$), $\mathrm{NAD}(\mathrm{P}) \mathrm{H}$ oxidase and 
xanthine oxidase activity were significantly increased in ZDF rats; but, administration of anti$\mathrm{TNF}$ to $\mathrm{ZDF}$ rats attenuated $\mathrm{NAD}(\mathrm{P}) \mathrm{H}$ oxidase activity and xanthine oxidase activity. Our findings indicate that TNF contributes to endothelial dysfunction in type 2 diabetes via increasing $\mathrm{ONOO}^{-}, \mathrm{H}_{2} \mathrm{O}_{2}$, and $\mathrm{O}_{2}{ }^{.-}$.

Roles of TNF and TNFRs in endothelialdependent and NO-mediated vasodilation in type 2 diabetes. Understanding endothelial dysfunction is critical because this condition precedes the development of diabetic vascular disease; thus if endothelial dysfunction can be rectified, the progression of vascular disease may be halted. Accordingly, we determined the role of TNF in endothelial function in ZDF rats by establishing the expression of this cytokine and its receptors, and production of ROS. Clinical and experimental studies have demonstrated that cardiac pump function is compromised in type 2 diabetes, suggesting that alterations in cardiac tissue metabolism in the diabetic state are responsible for this impairment (14). Changes in coronary vascular function can lead to a mismatch of myocardial supply and demand, thereby provoking ischemic episodes in the diabetic heart. In humans, vasodilation of coronary arteries was also altered after pharmacological (ACh) or mechanical (cold test) stimuli, but these abnormalities of large vessels were not associated with angiographic lesions, and are independent of other cardiovascular risk factors (1), suggesting impaired endothelial function without any anatomical lesions. Bagi et al. (1) have described that agonist- and flow-induced dilation of coronary arteries was impaired in type 2 diabetic mice. Furthermore, Miura et al. (12) confirmed the impairment of coronary microvascular function in human coronary arteries isolated from patients affected by type 1 or type 2 diabetes mellitus: coronary arteries showed a reduced vasodilation to hypoxia due to a reduced activity of ATP-sensitive potassium channels. Our results are consistent with these studies: in ZDF rats, dilation to $\mathrm{ACh}$, or flow, was blunted compared to lean rats, but SNPinduced dilation was comparable. Neutralizing antibodies to TNF, or blockade of $\mathrm{NAD}(\mathrm{P}) \mathrm{H}$ oxidase and xanthine oxidase, partially restored endothelium-dependent, NO-mediated coronary arteriolar dilation in ZDF rats, but the antibodies to TNF did not alter the vasodilation in lean rats.

Yudkin et al. (24) showed that CRP, IL-6 and TNF are elevated in association with quantitative measures of insulin resistance and features of the insulin resistance syndrome. Rask-Madsen et al. (17) have recently demonstrated that TNF is able to inhibit insulin-stimulated glucose uptake as well as endothelium-dependent vasodilation in humans and that inhibitory effect on vasodilator function is larger during local elevation of plasma insulin; the authors also speculated that TNF blocked NO production stimulated by insulin and ACh. TNF inhibits NO-mediated endothelium-dependent vasorelaxation in small coronary arteries via sphingomyelinase activation and consequent $\mathrm{O}_{2}{ }^{.-}$ production in endothelial cells (26). Gilmont et al. have shown a direct effect of TNF on endothelial cells, whereby the cells are rendered more susceptible to oxidant injury accompanying reperfusion in rat pulmonary artery endothelial cells (3).

Our RT-PCR analysis demonstrated that TNFR1 and TNFR2 mRNA were detected in the hearts and isolated small coronary arteries from lean and ZDF rats. The diverse signaling events that regulate varied TNF responses are all initiated by the binding of heterotrimeric ligand to one of two cell surface receptors (TNFR1 and TNFR2) (23). The connection between TNF and type 2 diabetes-induced endothelial dysfunction was established in the functional results (anti-TNF restored endothelium-dependent vasodilation in ZDF rats). We found that the expression of TNF is elevated in isolated coronary arteries in ZDF rats compared to lean controls. We also found that the expression of the TNF receptor, TNFR1 (but not TNFR2) was elevated in ZDF rats compared to lean rats.

It is provocative to note that despite the similarities in glucose, body weight, lipid level, insulin resistance, and blood pressure in the advanced diabetic animals, endothelial function was better in ZDF treated with anti-TNF than in the control. This suggests that TNF is the key cytokine, which induced endothelial dysfunction in the advanced type 2 diabetes (26 to 32 weeks old ZDF rats). These results are also consistent with our previous study on Zucker obese fatty rats 
(16), and provide new information under more advanced pathophysiological conditions, regarding the role of TNF in endothelial dysfunction in type 2 diabetes and the mechanisms by which TNF induces these pathophysiological conditions. Type 2 diabetes-induced coronary endothelial dysfunction were mediated by TNF and we further investigated the causal mechanisms.

Roles of $\mathrm{ROS}\left(\mathrm{O}_{2} \cdot-, \mathrm{ONOO}^{-}\right.$and $\left.\mathrm{H}_{2} \mathrm{O}_{2}\right)$ in type 2 diabetes. TNF stimulates $\mathrm{O}_{2}{ }^{--}$production in neutrophils and endothelial cells, reportedly via ceramide-activated protein kinase (CAPK), $\mathrm{NAD}(\mathrm{P}) \mathrm{H}$ oxidase, xanthine oxidase, or NO synthase, etc. $(18,26)$. Diabetes has been associated with an increased generation of oxygen free radicals as well. Many experimental studies suggest that increased $\mathrm{O}_{2}{ }^{-}$production accounts for a significant proportion of the $\mathrm{NO}$ deficit in diabetic vessels. Potential sources of vascular $\mathrm{O}_{2}{ }^{\cdot-}$ production include $\mathrm{NAD}(\mathrm{P}) \mathrm{H}$-dependent oxidases, xanthine oxidase, lipoxygenase, mitochondrial oxidase and $\mathrm{NO}$ synthase. $\mathrm{NAD}(\mathrm{P}) \mathrm{H}$ oxidases appear to be the principal source of $\mathrm{O}_{2}{ }^{\cdot-}$ production in several animal models of vascular disease, including diabetes (7, 18, 26). Furthermore, NAD $(\mathrm{P}) \mathrm{H}$ oxidase proteins and activity are present in human blood vessels, including atherosclerotic coronary arteries, and in saphenous veins and mammary arteries from patients with coronary artery disease, which suggests that this oxidase system plays an important role in cardiovascular disease (2). Guzik et al.(5) have described the mechanisms of increased $\mathrm{O}_{2}{ }^{-}$production in human diabetes mellitus. They found that basal $\mathrm{O}_{2}{ }^{-}$release was significantly elevated in vessels from patients with diabetes: Western blot analysis showed increased levels of the p22 phox membrane-bound subunit and the p67 phox and p47 phox cytosolic subunits in both veins and arteries from diabetic patients. The impaired endothelial function may be the direct result of the overproduction of $\mathrm{O}_{2}{ }^{-}$during the development of type 2 diabetes. $\mathrm{O}_{2}{ }^{-}$is the chemical precursor to many ROS, such as $\mathrm{H}_{2} \mathrm{O}_{2}$, and $\mathrm{ONOO}^{-} \cdot \mathrm{H}_{2} \mathrm{O}_{2}$ is formed by the spontaneous or enzymatic dismutation (via superoxide dismutase) of $\mathrm{O}_{2}{ }^{-}$and is in itself a potent oxidant. $\mathrm{ONOO}^{-}$is formed by the reaction between $\mathrm{NO}$ and $\mathrm{O}_{2}{ }^{-}$and is another potent oxidant. Our study shows that in addition to $\mathrm{O}_{2}{ }^{-}$, the production of $\mathrm{H}_{2} \mathrm{O}_{2}$ and $\mathrm{ONOO}^{-}$were also higher in $\mathrm{ZDF}$ rats, indicating ROS plays a significant role in advanced type 2 diabetes.

To establish if $\mathrm{NAD}(\mathrm{P}) \mathrm{H}$ oxidase, xanthine oxidase and/or mitochondraia respiratory chain are the pathway for $\mathrm{O}_{2}{ }^{-}$production, we administered the $\mathrm{NAD}(\mathrm{P}) \mathrm{H}$ oxidase inhibitor, apocynin, to determine if vasodilation to $\mathrm{ACh}$ would be restored in $\mathrm{ZDF}$ rats. Our results showed that apocynin and oxypurinol rescued dilation to $\mathrm{ACh}$ in $\mathrm{ZDF}$ rats, but did not affect the response in lean rats. These results demonstrated that the greater amount of generation of $\mathrm{O}_{2}{ }^{-}$in ZDF rats is also attributed to activation of xanthine oxidase, which is downstream from sphingomyelinase. Taken together, our results further support that TNF and $\mathrm{O}_{2}{ }^{-}$are connected in the production of oxidative stress and endothelial dysfunction in type 2 diabetes. Our results regarding type 2 diabetes diverge when considering the enzyme system responsible for this pathophysiological disease. In our previous study in prediabetic metabolic syndrome (16), we found $\mathrm{NAD}(\mathrm{P}) \mathrm{H}$ oxidase assumed prominence in $\mathrm{O}_{2}{ }^{-}$generation, but that in type 2 diabetes, an increased amount of superoxides were generated by both $\mathrm{NAD}(\mathrm{P}) \mathrm{H}$ and xanthine oxidases.

It has been reported that $\mathrm{O}_{2}{ }^{-}$and $\mathrm{NO}$ combine to form peroxynitrite, and limiting production of $\mathrm{O}_{2}{ }^{-}$thus increase the bioavailability and measurements of NO. In our study, antibodies to TNF attenuates $\mathrm{O}_{2}{ }^{\cdot-}, \mathrm{H}_{2} \mathrm{O}_{2}$, and $\mathrm{ONOO}^{-}$production in $\mathrm{ZDF}$ rats. We found that inhibition of both xanthine oxidase and $\mathrm{NAD}(\mathrm{P}) \mathrm{H}$ oxidase are required to block ROS production in ZDF rats. We believe that the production of authentic NO increases following inhibition of xanthine oxidase and $\mathrm{NAD}(\mathrm{P}) \mathrm{H}$ oxidase in the ZDF rats. Our previous study (16) suggested TNF contributes to endothelial dysfunction in prediabetic metabolic syndrome (Zucker obese fatty rats, young group of the rats at 12-16 weeks) and in 12-16 weeks lepr ${ }^{\mathrm{db}}$ mice (young type 2 diabetic mouse models), and that anti-TNF may rescue this impairment. However, this was not the situation in the more advanced condition of type 2 diabetes (26-32 weeks of ZDF rats). We found that the severe impaired

C 2010 by NWPII. All rights reserved. 
vasodilation to $\mathrm{ACh}$ resulted from increased expression/production of TNF in type 2 diabetes, which stimulates endothelial generation of $\mathrm{O}_{2}{ }^{--}$ radicals via $\mathrm{NAD}(\mathrm{P}) \mathrm{H}$ oxidase and xanthine oxidase in the microvasculature and contributes to the observed endothelial dysfunction. Our results demonstrate that the endothelial dysfunction occurring in type 2 diabetes is the result of effects of the inflammatory cytokine TNF and mainly through the over-expression of TNFR1. Selective modulation of TNF and its receptor signaling may provide a novel therapeutic target to remediate coronary diseases associated with TNF activation. It is reported (27) that oxidative stress mediated by hyperglycaemia-induced generation of reactive oxygen species (ROS) contributes significantly to the development and progression of diabetes and related vascular complications. $\mathrm{NAD}(\mathrm{P}) \mathrm{H}$ oxidase has been implicated as the major source of ROS generation in the vasculature in response to high glucose and advanced glycation end-products. Sustained activation of $\mathrm{NAD}(\mathrm{P}) \mathrm{H}$ oxidase in diabetes may diminish intracellular levels of NADPH, an essential cofactor for endothelial NO synthase (eNOS) and several antioxidant systems. Recent evidence suggests that basal ROS production via $\mathrm{NAD}(\mathrm{P}) \mathrm{H}$ oxidase may upregulate antioxidant enzyme defenses via redox signalling. (27)

Knowledge gained from this study may help to further understand the increased cardiovascular risk and development of chronic vascular disease in diabetes. The inflammatory cytokine, TNF, plays a pivotal role in endothelial dysfunction in diabetes. This work may provide exciting new targets for the development of drugs for cardiovascular disorders in ischemic heart disease, obesity, diabetes and hypertension.

\section{ACKNOWLEDGEMENT}

This study was supported by grants from American Heart Association Scientist Development Grant (110350047A), Pfizer Atorvastatin Research Award (2004-37), NIH grants (RO1-HL077566 and RO1-HL085119) to Dr. Cuihua Zhang.

\section{REFERENCES}

1. Bagi Z, Koller A, and Kaley G. SuperoxideNO interaction decreases flow- and agonistinduced dilations of coronary arterioles in Type 2 diabetes mellitus. Am J Physiol Heart Circ Physiol 285: H1404-1410, 2003.

2. Cai $\mathbf{H}$ and Harrison DG. Endothelial dysfunction in cardiovascular diseases: the role of oxidant stress. Circ Res 87: 840-844, 2000.

3. Gilmont RR, Dardano A, Engle JS, Adamson BS, Welsh MJ, Li T, Remick DG, Smith DJ, Jr., and Rees RS. TNF-alpha potentiates oxidant and reperfusion-induced endothelial cell injury. J Surg Res 61: 175-182, 1996.

4. Grundy SM, Benjamin IJ, Burke GL, Chait A, Eckel RH, Howard BV, Mitch W, Smith SC, Jr., and Sowers JR. Diabetes and cardiovascular disease: a statement for healthcare professionals from the American Heart Association. Circulation 100: 11341146, 1999.

5. Guzik TJ, Mussa S, Gastaldi D, Sadowski J, Ratnatunga C, Pillai R, and Channon KM. Mechanisms of increased vascular superoxide production in human diabetes mellitus: role of $\mathrm{NAD}(\mathrm{P}) \mathrm{H}$ oxidase and endothelial nitric oxide synthase. Circulation 105: 1656-1662, 2002.

6. Keith ME, Norwich KH, and Jeejeebhoy KN. Nutrition support affects the distribution and organ uptake of cachectin/tumor necrosis factor in rats. JPEN J Parenter Enteral Nutr 19: 341-350, 1995.

7. Kolesnick $\mathbf{R}$ and Golde DW. The sphingomyelin pathway in tumor necrosis factor and interleukin-1 signaling. Cell 77: 325-328, 1994.

8. Kranidis A, Zamanis N, Mitrakou A, Patsilinakos S, Bouki T, Tountas N, Anthopoulos P, Raptis S, and Anthopoulos L. Coronary microcirculation evaluation with transesophageal echocardiography Doppler in type II diabetics. Int J Cardiol 59: 119-124, 1997.

9. Lattime EC and Stutman O. Thymic lymphomas mediate non-MHC-restricted, 
TNF-dependent lysis of the murine sarcoma WEHI-164. Cell Immunol 136: 69-79, 1991.

10. Mayhan WG. Impairment of endotheliumdependent dilatation of the basilar artery during diabetes mellitus. Brain Res 580: 297302, 1992.

11. Mayhan WG, Simmons LK, and Sharpe GM. Mechanism of impaired responses of cerebral arterioles during diabetes mellitus. Am J Physiol 260: H319-326, 1991.

12. Miura H, Wachtel RE, Loberiza FR, Jr., Saito T, Miura M, Nicolosi AC, and Gutterman DD. Diabetes mellitus impairs vasodilation to hypoxia in human coronary arterioles: reduced activity of ATP-sensitive potassium channels. Circ Res 92: 151-158, 2003.

13. Nahser PJ, Jr., Brown RE, Oskarsson H, Winniford MD, and Rossen JD. Maximal coronary flow reserve and metabolic coronary vasodilation in patients with diabetes mellitus. Circulation 91: 635-640, 1995.

14. Nitenberg A, Paycha F, Ledoux S, Sachs R, Attali JR, and Valensi P. Coronary artery responses to physiological stimuli are improved by deferoxamine but not by Larginine in non-insulin-dependent diabetic patients with angiographically normal coronary arteries and no other risk factors. Circulation 97: 736-743, 1998.

15. Nygard O, Nordrehaug JE, Refsum H, Ueland PM, Farstad M, and Vollset SE. Plasma homocysteine levels and mortality in patients with coronary artery disease. $N$ Engl J Med 337: 230-236, 1997.

16. Picchi A, Gao X, Belmadani S, Potter BJ, Focardi M, Chilian WM, and Zhang C. Tumor necrosis factor-alpha induces endothelial dysfunction in the prediabetic metabolic syndrome. Circ Res 99: 69-77, 2006.

17. Rask-Madsen C, Dominguez $\mathbf{H}$, Ihlemann N, Hermann $T$, Kober $L$, and TorpPedersen C. Tumor necrosis factor-alpha inhibits insulin's stimulating effect on glucose uptake and endothelium-dependent vasodilation in humans. Circulation 108: 1815-1821, 2003.

18. Sorescu D and Griendling KK. Reactive oxygen species, mitochondria, and $\mathrm{NAD}(\mathrm{P}) \mathrm{H}$ oxidases in the development and progression of heart failure. Congest Heart Fail 8: 132140, 2002.

19. Stampfer MJ, Malinow MR, Willett WC, Newcomer LM, Upson B, Ullmann D, Tishler PV, and Hennekens CH. A prospective study of plasma homocyst(e)ine and risk of myocardial infarction in US physicians. Jama 268: 877-881, 1992.

20. Tartaglia LA and Goeddel DV. Two TNF receptors. Immunol Today 13: 151-153, 1992.

21. Tesfamariam B, Brown ML, Deykin D, and Cohen RA. Elevated glucose promotes generation of endothelium-derived vasoconstrictor prostanoids in rabbit aorta. $J$ Clin Invest 85: 929-932, 1990.

22. Tesfamariam B, Jakubowski JA, and Cohen RA. Contraction of diabetic rabbit aorta caused by endothelium-derived PGH2TxA2. Am J Physiol 257: H1327-1333, 1989.

23. Wallach D, Varfolomeev EE, Malinin NL, Goltsev YV, Kovalenko AV, and Boldin MP. Tumor necrosis factor receptor and Fas signaling mechanisms. Annu Rev Immunol 17: 331-367, 1999.

24. Yudkin JS, Stehouwer CD, Emeis JJ, and Coppack SW. C-reactive protein in healthy subjects: associations with obesity, insulin resistance, and endothelial dysfunction: a potential role for cytokines originating from adipose tissue? Arterioscler Thromb Vasc Biol 19: 972-978, 1999.

25. Zhang $\mathrm{C}, \mathrm{Xu} \mathbf{X}$, Potter BJ, Wang W, Kuo L, Michael L, Bagby GJ, and Chilian WM. TNF-alpha contributes to endothelial dysfunction in ischemia/reperfusion injury. Arterioscler Thromb Vasc Biol 26: 475-480, 2006.

26. Zhang DX, Yi FX, Zou AP, and Li PL. Role of ceramide in TNF-alpha-induced impairment of endothelium-dependent vasorelaxation in coronary arteries. Am J Physiol Heart Circ Physiol 283: H1785-1794, 2002.

27. L. Gao, G. E. Mann. Vascular NAD(P)H oxidase activation in diabetes: a double-edged sword in redox signaling. Cardiovasc Res. 82(1):9-20. 2009.

(C) 2010 by NWPII. All rights reserved. 